OPEN ACCESS

Edited by:

Aldo Torre,

Instituto Nacional de Ciencias

Médicas y Nutrición Salvador Zubirán

(INCMNSZ), Mexico

Reviewed by:

Javier Gomez-Ambrosi,

University Clinic of Navarra, Spain

Giovanni Tarantino,

University of Naples Federico II, Italy

*Correspondence:

Andrew J. Murray

ajm267@cam.ac.uk

Specialty section:

This article was submitted to

Gastroenterology,

a section of the journal

Frontiers in Medicine

Received: 04 August 2021 Accepted: 10 September 2021

Published: 06 October 2021

Citation:

Holzner LMW and Murray AJ (2021)

Hypoxia-Inducible Factors as Key

Players in the Pathogenesis of

Non-alcoholic Fatty Liver Disease and Non-alcoholic Steatohepatitis.

Front. Med. 8:753268.

doi: $10.3389 /$ fmed.2021.753268

\section{Hypoxia-Inducible Factors as Key Players in the Pathogenesis of Non-alcoholic Fatty Liver Disease and Non-alcoholic Steatohepatitis}

\author{
Lorenz M. W. Holzner and Andrew J. Murray* \\ Department of Physiology, Development and Neuroscience, University of Cambridge, Cambridge, United Kingdom
}

Non-alcoholic fatty liver disease (NAFLD) and its more severe form non-alcoholic steatohepatitis (NASH) are a major public health concern with high and increasing global prevalence, and a significant disease burden owing to its progression to more severe forms of liver disease and the associated risk of cardiovascular disease. Treatment options, however, remain scarce, and a better understanding of the pathological and physiological processes involved could enable the development of new therapeutic strategies. One process implicated in the pathology of NAFLD and NASH is cellular oxygen sensing, coordinated largely by the hypoxia-inducible factor (HIF) family of transcription factors. Activation of HIFs has been demonstrated in patients and mouse models of NAFLD and NASH and studies of activation and inhibition of HIFs using pharmacological and genetic tools point toward important roles for these transcription factors in modulating central aspects of the disease. HIFs appear to act in several cell types in the liver to worsen steatosis, inflammation, and fibrosis, but may nevertheless improve insulin sensitivity. Moreover, in liver and other tissues, HIF activation alters mitochondrial respiratory function and metabolism, having an impact on energetic and redox homeostasis. This article aims to provide an overview of current understanding of the roles of HIFs in NAFLD, highlighting areas where further research is needed.

Keywords: non-alcoholic fatty liver disease (NAFLD), non-alcoholic steatohepatitis (NASH), hypoxia-inducible factor (HIF), chronic intermittent hypoxia, obstructive sleep apnea, fibrosis, metabolism, inflammation

\section{INTRODUCTION}

Non-alcoholic fatty liver disease (NAFLD) is a progressive, widespread form of chronic liver disease with a large global burden. Worldwide, around 25\% of the population have NAFLD and its prevalence is increasing (1). NAFLD initially presents as relatively benign fatty liver but worsens with time, leading to fibrosis and the inflammatory, more severe non-alcoholic steatohepatitis (NASH). Eventually, even cirrhosis or hepatocellular carcinoma can occur (2). It is also an important independent risk factor for cardiovascular disease (1). Despite this, specific treatment options for NAFLD are lacking. In order to develop such specific treatments, a better understanding of disease mechanisms and the (patho-)physiological signalling systems involved in NAFLD progression are needed. 
The hypoxia-signalling system has been implicated in the pathogenesis of NAFLD (3). Central to cellular oxygen-sensing is the hypoxia-inducible factor (HIF) family of transcription factors which regulate the expression of genes underpinning the cellular and systemic response to hypoxia. HIFs are heterodimers, made up of an alpha subunit (of which three are currently known: HIF $1 \alpha, \operatorname{HIF} 2 \alpha$, and HIF $3 \alpha$ ), and a beta subunit (HIF1 $\beta$ ). Current understanding of the regulation and function of HIF1 $\alpha$ and HIF $2 \alpha$, is much greater than that of HIF $3 \alpha$, which remains under-investigated (4). The 2019 Nobel Prize in Physiology or Medicine was awarded to William Kaelin Jr., Peter J. Ratcliffe, and Gregg L. Semenza for their work in revealing how HIFs sense oxygen levels and coordinate the cellular response to hypoxia. The sensing mechanism, which has been reviewed elsewhere (5), involves targeted destruction of HIF $\alpha$ subunits in the presence of oxygen (Figure 1). Under normoxic conditions, HIF-prolyl hydroxylase domain proteins (PHD13) hydroxylate proline residues in cytoplasmic HIF $\alpha$ subunits in an oxygen-dependent manner. This allows recognition by the E3 ubiquitin ligase von-Hippel Lindau protein (VHL), leading to ubiquitination of HIF $\alpha$ and subsequent proteasomal degradation. PHD-mediated hydroxylation does not occur in hypoxia, allowing HIF $\alpha$ stabilisation, translocation to the nucleus and dimerization with HIF1 $\beta$. Activated HIFs bind to hypoxia response elements in the promoters of target genes, leading to the transcription of genes required for adaptation to hypoxia, such as Vegfa, encoding vascular endothelial growth factor, and genes encoding many glycolytic enzymes (6). Owing to their roles in the regulation of diverse processes such as metabolism and angiogenesis, there is great potential for the involvement of HIFs in multiple key aspects of NAFLD, and accumulation of HIFs has been demonstrated to occur in the livers of patients with NAFLD (3). This makes HIF signalling a promising therapeutic target for this disease, especially since pharmacological modulators of the HIF pathway already exist (7-9).

\section{Potential Mechanisms of HIF Activation in NAFLD}

The canonical driver of HIF activation is tissue hypoxia. Hypoxia in the liver has been shown to occur in mice fed a high fat diet (HFD) for 8 weeks, though it remains unclear how this

\footnotetext{
Abbreviations: Acox, Acyl coenzyme A oxidase; Acta, $\alpha$ smooth muscle actin (gene); $\alpha$-SMA, $\alpha$ smooth muscle actin (protein); ATP, Adenosine triphosphate; BDL, Bile duct ligation; CD36, Cluster of differentiation 36; $\mathrm{CIH}$, Chronic intermittent hypoxia; Col1a1, Type 1 Collagen; Cpt1, Carnitine palmitoyltransferase 1; ECM, Extracellular matrix; Epas1, Endothelial PAS domain containing protein (gene); FAO, Fatty acid oxidation; Fas, Fatty acid synthase; HFD, High fat diet; HIF, Hypoxia-inducible factor; HRGP, Histidine rich glycoprotein; HSC, Hepatic stellate cell; IL-1b, Interleukin 1b; Irs2, Insulin receptor substrate 2; Lox, Lysyl oxygenase; MCP1, Macrophage attractant protein 1; NAFLD, Non-alcoholic fatty liver disease; NASH, Non-alcoholic steatohepatitis; $\mathrm{NF}-\kappa \mathrm{B}$, nuclear factor kappa-light-chain-enhancer of activated B cells; OSAObstructive sleep apnea; PAI-1, Plasminogen activator-inhibitor 1; PDGF, Platelet derived growth factor; Pepck, Phosphoenolpyruvate carboxykinase; Pgcla, Peroxisome proliferator-activated receptor gamma coactivator $1 \alpha$; Phd, Prolyl hydroxylase domain protein (gene); PPAR, Peroxisome proliferator-activated receptor; ROS, Reactive oxygen species; Scd1, Stearoyl coenzyme A-desaturase 1; Tnfa, Tumour necrosis factor $1 \alpha$; Vegf, Vascular endothelial growth factor; Vhl, Von Hippel-Lindau protein (gene).
}

local hypoxia develops (10). The liver displays a steep oxygen gradient, with higher partial pressures of oxygen in the periportal regions, but lower oxygenation in perivenous regions (11). In NAFLD, this gradient could become dysregulated, leading to hepatic hypoxia, and this has been observed using pimonidazole staining in mice fed a HFD (12). Pimonidazole is a small molecule that reacts with thiol groups in proteins and peptides specifically under hypoxic conditions allowing for the detection of hypoxia using immunohistochemical techniques (13). Dysregulation of the oxygen gradient in the liver could result from increased size of hepatocytes (which increases the diffusion distance for oxygen), e.g., due to steatosis, or from increased oxygen consumption, which may occur in early stages of NAFLD development as appears to be the case in HFD fed rats $(14,15)$. This increase in oxygen consumption may be a result of increased fat oxidation to avoid lipid accumulation in a state of high fat intake. In addition to hypoxia, HIF stabilisation also occurs in response to reactive oxygen species (ROS) production (16), which is commonly seen in animals fed a HFD (17), and can be caused by cholesterol accumulation (18). ROS production could also result from reduced levels of the sirtuin SIRT4, which have been observed in patients with NAFLD (19). HIF activation can also result from succinate accumulation (20). SIRT1 has also been shown to be an important component of HIF activation (21). However, it should be noted that SIRT1 is generally downregulated in patients with NAFLD (22), and it is therefore unclear whether this mechanism is involved in regulation of HIFs in this context. While localised hypoxia has been demonstrated in steatotic mouse livers (10), it remains unclear whether this is driven by increased diffusion distance, increased oxygen consumption, or a combination of both. Further, other mechanisms of HIF activation, such as ROS production and importantly, chronic intermittent hypoxia $(\mathrm{CIH})$, remain under-investigated in this context. $\mathrm{CIH}$ occurs in humans with obstructive sleep apnoea (OSA), which causes nocturnal bouts of low blood oxygen caused by breathing difficulties (23). It is common in patients with obesity (24), and has been linked to NAFLD severity (25), but it remains unclear to what extent it is required for HIF activation in patients with NAFLD, and whether HIF mediated pathophysiological mechanisms differ between patients of NAFLD with and those without OSA. It should be noted that while rodents do not spontaneously develop OSA (meaning $\mathrm{CIH}$ does not occur in rodent models of NAFLD), HIF accumulation has been demonstrated in the livers of rodent models of NAFLD. This supports the view that $\mathrm{CIH}$ is not necessarily a requirement for HIF activation in NAFLD. The uncertainty around the mechanism driving HIF activation in NAFLD is of note, as mechanistic into this very common disease remains lacking (26), making it crucial to address such gaps in our understanding of the pathology of NAFLD.

\section{Metabolic Roles of HIFs in NAFLD}

Regulation of cellular metabolism is a major canonical function of HIFs. In order to maintain energy charge in hypoxia, HIFs increase the expression of genes encoding glycolytic enzymes such as lactate dehydrogenase (27), while repressing the expression of genes involved in oxidative metabolism, 


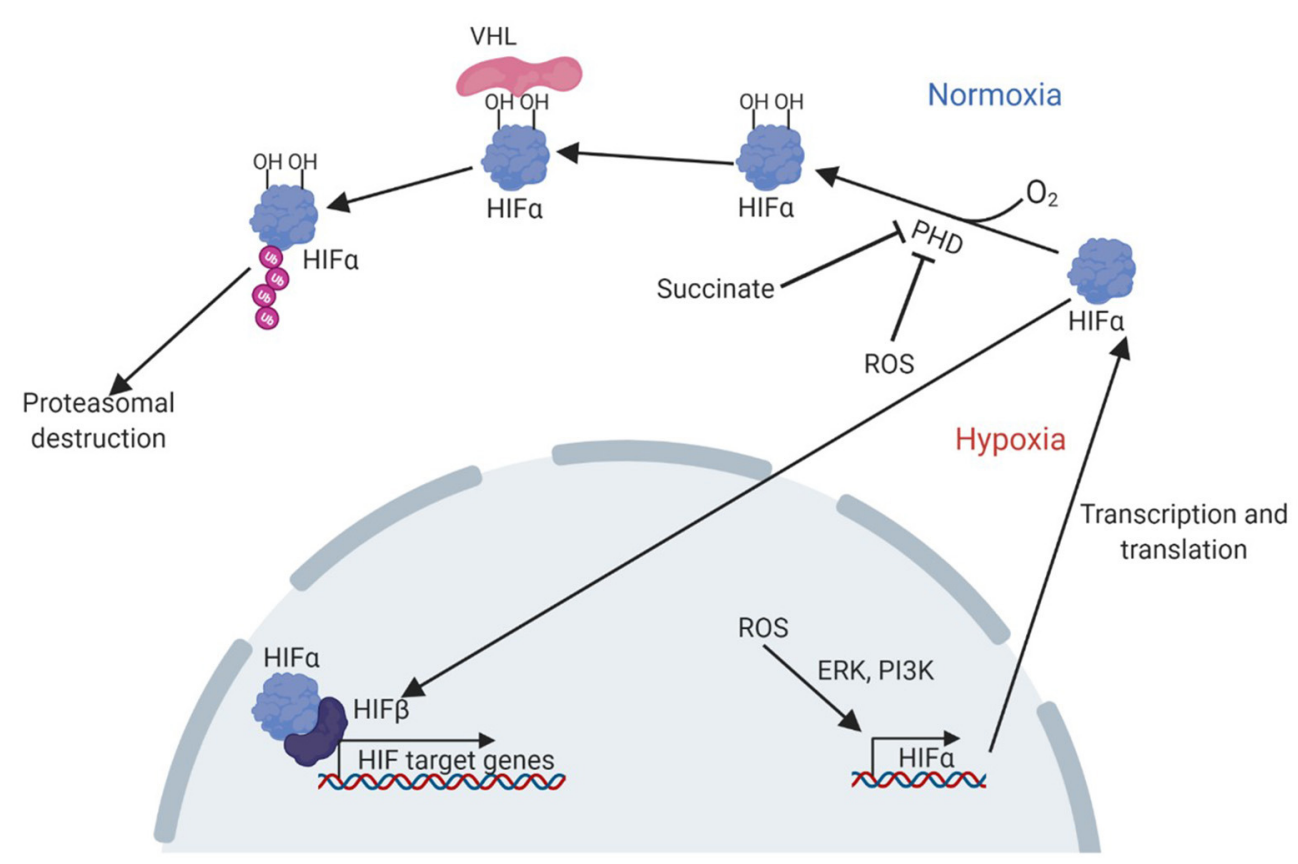

FIGURE 1 | Pathway of HIF activation in hypoxia. Adapted from Lee et al. (7). Under normoxic conditions, PHD enzymes hydroxylate proline residues in the HIF $\alpha$ subunit, in an oxygen-dependent manner. The hydroxylated residues are bound by VHL, which ubiquitinates HIF $\alpha$ allowing recognition and destruction of HIF $\alpha$ by the proteasome. Under hypoxic conditions, hydroxylation cannot occur and HIF $\alpha$ can instead translocate to the nucleus, bind HIF $\beta$ and other cofactors to activate transcription of target genes. HIF accumulation can also result from PHD inhibition by succinate or ROS, or by increased transcription and translation due to a ROS induced, ERK and PI3K mediated pathway. ERK, extracellular-signal related kinase; HIF, hypoxia-inducible factor; PHD, prolyl hydroxylase domain proteins; PI3K, phosphoinositide 3-kinase; VHL, Von Hippel Lindau protein.

particularly fatty acid oxidation (FAO) (28). This serves to decrease oxygen requirements for ATP production, and protects against cellular damage in short-term hypoxia. However, chronic activation of HIFs in patients and models of fatty liver disease (3) may inhibit FAO to such an extent that it leads to or worsens hepatic lipid accumulation. HIF activation also appears to worsen steatosis by increasing the expression of genes required for lipogenesis, and the uptake and storage of lipids (9). Under normal circumstances, this may be an adaptive response to acute hypoxia, acting to store energy sources that cannot be utilised due to the general limitation on oxidative metabolism, and to package potentially toxic fatty acids as less harmful triglycerides. Overall, however, the resulting lipid accumulation appears to represent a harmful role for HIFs in steatotic liver diseases, such as NAFLD. It may also explain part of the association between severe OSA severity and incidence of NAFLD (29). Evidence of an insulinsensitising role of HIFs in metabolic disease (30) complicates the overall effect of HIF activation in fatty liver disease, which is typically associated with insulin resistance (31).

Considerable evidence points toward HIF-mediated downregulation of FAO in hepatic steatosis. In particular, HIF $2 \alpha$ activation, which occurs in the livers of patients with NAFLD as well as in mouse models (3), appears to worsen lipid accumulation (see Figure 2). Early studies in Vhl-deficient mice, showed that HIF2 $\alpha$, but not HIF1 $\alpha$, is responsible for the suppression of FAO in these mice (32-34). Vhl-deficient mice had lower expression of peroxisome proliferator-activated receptor $\alpha(\mathrm{PPAR} \alpha)$-target genes, such as carnitine-palmitoyl transferase 1 (Cpt1) and acyl CoA oxidase (Acox), lowering fatty acid-supported oxidative phosphorylation (33). PPARs are a family of transcription factors activated by unsaturated fatty acids, amongst other ligands. They play a key role in the control of fatty acid metabolism, and PPAR $\alpha$ in particular is a major regulator of FAO in the liver (35). The reduced expression of PPAR $\alpha$ target genes in Vhl-deficient mice was prevented by deletion of Epas1 (endothelial PAS domain containing protein 1, the gene encoding HIF2 $\alpha$ ) but not Hif1a deletion (32). Similarly, primary hepatocytes from $V h l$-deficient mice showed increased lipid accumulation alongside low expression of PPAR $\alpha$ target genes (36). Indeed, HIF $2 \alpha$ binds the PPAR $\alpha$ promoter to repress its expression in HEK293 cells (28). Hif2a deletion or knockdown using siRNA prevents hypoxia-associated lipid accumulation in the human hepatocellular carcinoma HepG2 cell line $(37,38)$. Hypoxia appears to cause lipid accumulation in these cells by stabilising HIF2 $\alpha$, thereby lowering expression of FAO genes such as Cpt1 and PPAR $\gamma$ coactivator $\alpha(P g c 1 \alpha)$ (38). Expression of these genes was normalised by Hif $2 a$ deletion, leading to decreased lipid accumulation. These studies demonstrate a potential role for HIF $2 \alpha$ activation in decreasing the capacity for FAO in the liver, which could worsen steatosis in the context of NAFLD, when dietary fat intake is typically high.

While it is clear that HIF, and in particular HIF $2 \alpha$, activation can limit FAO in the liver to worsen steatosis, the studies outlined above did not investigate whether this occurs in NAFLD. 


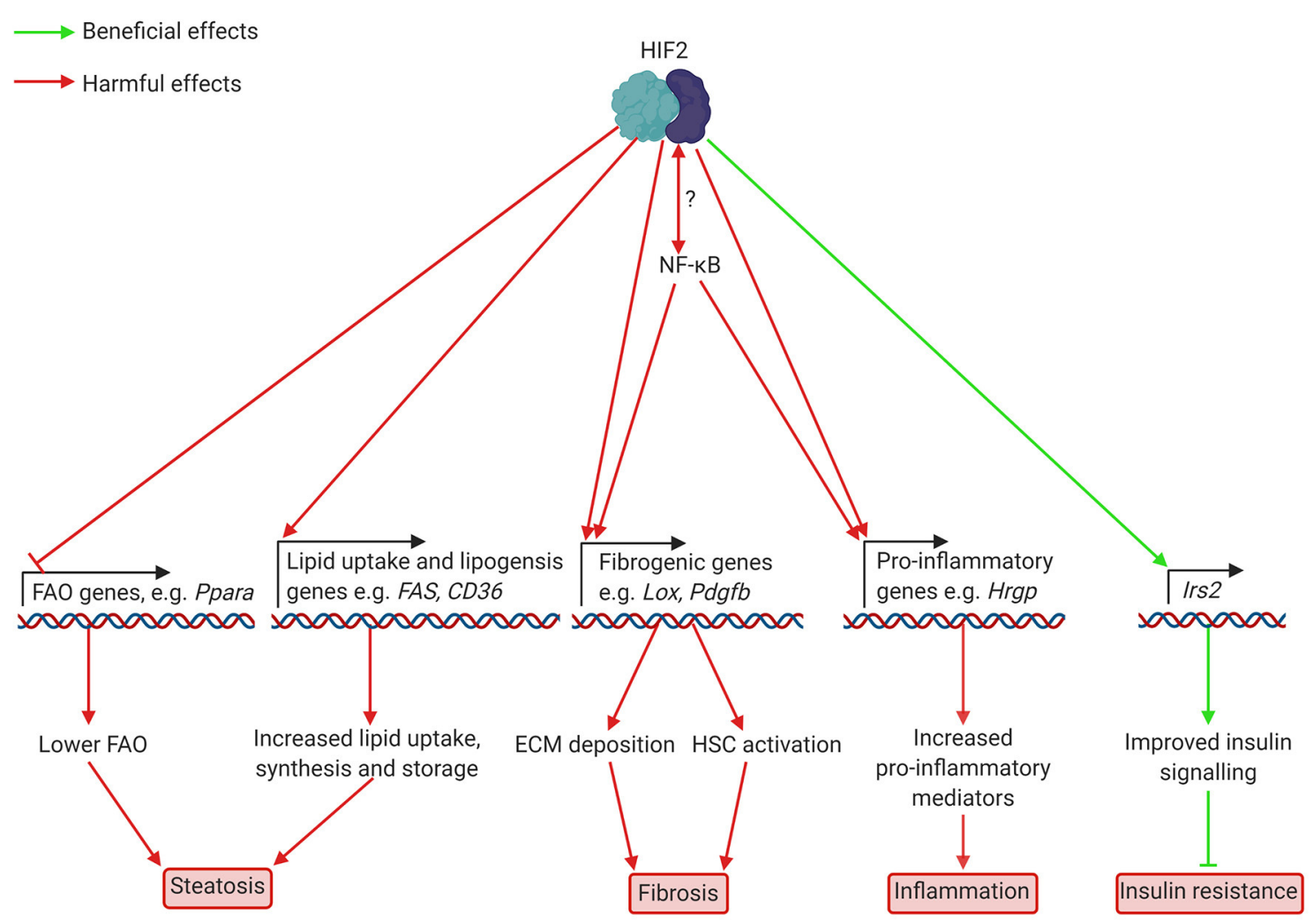

FIGURE 2 | Putatively beneficial and harmful effects of HIF2 activation in hepatocytes in NAFLD and NASH. HIF2 activation leads to lower expression of FAO genes, including Ppara, which encodes PPAR $\alpha$. This decreases FAO, leading to increased lipid accumulation. Higher levels of fibrogenic mediators such as LOX and potentially PAI-1, which are involved in ECM deposition, also occur as a result of HIF2 activation. Increased production of HSC activators may also occur but this has not yet been demonstrated in NAFLD/NASH. HIF2 mediated upregulation of the pro-inflammatory cytokine HRGP worsens inflammation. Interplay between HIF2 and $\mathrm{NF}-\kappa \mathrm{B}$ appears likely, but details of this interaction are unknown. Finally, increased transcription of the insulin signalling component Irs2 appears to improve insulin signalling to prevent insulin resistance. ECM, extracellular matrix; FAO, fatty acid oxidation; HIF, hypoxia-inducible factor; Hrgp, histidine rich glycoprotein; HSC, hepatic stellate cell; Irs2, insulin receptor substrate 2; Lox, lysyl oxidase; NF-кB, nuclear factor kappa-light-chain-enhancer of activated B cells; Ppara, peroxisome proliferator-activated receptor $\alpha$; Fas, fatty acid synthase; CD36, cluster of differentiation 36; Pdgfb, platelet derived growth factor b.

Studies in in vitro systems and animal models of NAFLD suggest that this is indeed the case. Mice exposed to a HFD to induce hepatosteatosis showed decreased lipid accumulation when treated with a HIF2 $\alpha$ antagonist (9), though FAO was not investigated in this study. In L02 human hepatocytes treated with fatty acids to model NAFLD in vitro, hypoxia worsened lipid accumulation, and this was associated with increased HIF2 $\alpha$ levels, decreased expression of Ppara and transcriptional targets of PPAR $\alpha$ such as Cpt1a and Acox, and lower oxidation of oleate (39). Silencing of Hif2a or treatment with a PPAR $\alpha$ agonist, normalised expression of FAO genes and oleate oxidation, thereby lowering lipid accumulation, while treatment with a PPAR $\alpha$ inhibitor prevented the beneficial effect of HIF $2 \alpha$-silencing. The authors also found that exposure of HFD fed mice to CIH, which models OSA, (see Table 2 for an overview of hypoxia animal and cell culture models) increased lipid accumulation in the liver and decreased the expression of FAO genes including Ppara, Cpt1a, and Acox2. PPAR $\alpha$ agonist treatment reversed the effects of hypoxia on steatosis. Chen et al. (39) did not investigate whether HIF2 $\alpha$ activation played a role in lipid accumulation in the absence of a hypoxic stimulus, although other studies have demonstrated that HIF $2 \alpha$ accumulation occurs in animal models of NAFLD without added hypoxia (40). Hepatic Hifl $\alpha$ deletion in a mouse model of NAFLD (mice fed a choline deficient diet), however, led to lower Lipin1 mediated PPAR $\alpha /$ PGC1 $\alpha$ pathway activation, which worsened steatosis relative to wild type mice (41), suggesting HIF1 $\alpha$ is required to maintain FAO in NAFLD. Further work is required to determine whether HIF $2 \alpha$ activation in NAFLD leads to lower FAO in animal models and human patients, especially in the absence of imposed hypoxia, though current evidence suggests that HIF $2 \alpha$ activation in NAFLD contributes to hepatic steatosis, and that HIF $2 \alpha$ activation can limit fatty acid oxidation, whereas HIF1 $\alpha$ appears to be required for FAO in NAFLD.

Increased lipogenesis is an important feature of NAFLD in human patients (42-44). Again, studies support a potential HIFmediated upregulation of this process in the context of NAFLD, although the current evidence for this role of HIF is conflicting. Studies of animal models of NAFLD suggest that HIF $2 \alpha$ activation in this disease context may drive increased lipogenesis, 
thus worsening lipid accumulation in the liver (see Figure 2). Treatment with the HIF $2 \alpha$ specific antagonist PT2399 lowered hepatic steatosis in HFD fed mice (9), and this was associated with decreased expression of lipogenic genes in the liver. In L02 human hepatocytes treated with fatty acids, hypoxia ( $1 \%$ oxygen in hypoxic cell culture incubators) increased the expression of lipogenic genes such as Fas and stearoyl CoA dehydrogenase $1(S c d 1)$, and this was normalised by HIF2 $\alpha$ silencing (39). Similarly, mice fed a HFD and subjected to CIH showed increased expression of Fas and $S c d 1$ relative to HFD fed mice not exposed to $\mathrm{CIH}$ (39). Conversely, oxygen therapy, which prevented HIF $2 \alpha$ accumulation, lowered hepatic steatosis in HFD fed mice, and lipid accumulation in primary hepatocytes exposed to fatty acids. This also normalised expression of lipogenic genes in both in vivo and in vitro models of hepatosteatosis (40). Thus, it appears that HIF $2 \alpha$-activation, resulting from hypoxia, worsens diet induced steatosis by activating lipogenic gene expression. However, it should be noted that genetic HIF2 $\alpha$ activation via Vhl disruption has been associated with decreased expression of lipogenic genes such as fatty acid synthase (Fas) (32), or, in other studies using the same mechanism, with only a temporary increase in lipogenic gene expression 3 days after the $V h l$ disruption (34). These conflicting results may be due to the differing mechanisms of HIF $2 \alpha$ activation. In addition to increasing lipogenesis, HIF $2 \alpha$ upregulation in NAFLD appears to increase lipid uptake by upregulating the fatty acid transporter Cluster of Differentiation 36 (CD36) (45). CD36 expression correlates with HIF $2 \alpha$ levels in patients with NAFLD, and hypoxia induces CD36 expression in mouse AML12 hepatocytes exposed to hypoxia (45). Therefore, there is evidence that HIF2 $\alpha$ activation (via genetic manipulation or hypoxia) can cause steatosis via inhibition of FAO and upregulation of lipid uptake, that liver hypoxia and HIF $2 \alpha$ activation occur in NAFLD, and that HIF $2 \alpha$ upregulates lipogenesis in diet-induced steatosis, which worsens lipid accumulation and can be prevented by treatment with HIF $2 \alpha$ antagonists. However, whether HIF2 $\alpha$ also impairs FAO in NAFLD remains unclear.

OSA also induces metabolic changes that may be mediated by HIF signalling. Levels of the CD36 are higher in the livers of patients with OSA than in those of healthy controls, and correlate with severity of OSA (46). CIH, which mimics OSA, induces the expression of lipogenic genes, such as Scd1, and CD36 in wild type (46) and $o b / o b$ mice (47). Moreover, CIH increased HIF $2 \alpha$, but not HIF1 $\alpha$ levels in HFD fed mice, while decreasing the expression of FAO genes such Cpt1a (39). Thus, it appears likely that HIF signalling decreases FAO and increases lipid uptake and lipogenesis to worsen steatosis in the context of OSA and CIH, though the link between CIH/OSA and HIF signalling has not yet been established.

The role that HIF activation plays in the context of obesity associated disease is complicated by evidence of a link between $\mathrm{HIF}$ and insulin signalling. Both HIF $1 \alpha$ and HIF $2 \alpha$ activation have been shown to alter insulin sensitivity and glucose handling, most likely in a beneficial manner (see Figures 2, 3). Owing to its role in upregulating glycolytic enzymes, it seems likely that HIF1 $\alpha$ could improve glucose handling in obesity and diabetes. Indeed, HIF1 $\alpha$ was upregulated in the livers of mice fed a high-fat, high-sucrose diet (30). Hepatocyte-specific deletion of Hifla was associated with worsened glucose handling and insulin sensitivity. This was associated with lower levels of hepatic glucokinase (30). Treatment of HFD fed mice with HIF1 $\alpha$ antisense oligonucleotides, however, decreased blood glucose and insulin levels (48). Unlike the hepatocyte-specific deletion employed by Ochiai et al. (30), this not only interfered with Hifla in the liver, but also in adipose tissue, which may explain the opposing results. Shin et al. (48) found increased energy expenditure and lower body weight in Hifla antisense oligonucleotide-treated animals. Hif1 $a$ antisense oligonucleotide treatment was also associated with lower liver steatosis, increased hepatic Ppara expression, and decreased expression of the lipogenic genes Scd1 and acetyl-CoA carboxylase (48), though again it is unclear whether this was due to Hifla interference in the liver or secondary to effects in other tissues. Overall, it appears that HIF1 $\alpha$ activation can have opposing effects on insulin sensitivity, which may be tissue specific. This could explain why OSA severity is associated with worsened insulin resistance in patients with NAFLD (29) while liver-specific deletion of Hifla worsens HFD induced glucose intolerance in mice (30).

HIF $2 \alpha$ also appears to be involved in hepatic insulin signalling, via direct modulation of components of the insulin-signalling pathway. Liver-specific HIF2 $\alpha$ (but not HIF1 $\alpha$ ) activation led to improved insulin tolerance and glucose handling (49). HIF2 $\alpha$ directly upregulates the insulin-signalling pathway component insulin receptor substrate 2 (IRS2) by binding to HREs in its promoter and Irs 2 was required for the HIF2 $\alpha$-mediated effect on insulin sensitivity. Similarly, hepatic deletion of Phd3, which specifically upregulated $\mathrm{HIF} 2 \alpha$, was associated with increased Irs2 transcription, improving insulin sensitivity (50). Again, this beneficial effect required both Hif2a and Irs2. Phd3 deletion was associated with lower expression of gluconeogenic [e.g., phosphoenolpyruvate carboxykinase (Pepck)] and lipogenic (e.g., Fas) genes. Interestingly, unlike other models of liver specific HIF2 $\alpha$ activation, Phd3 deletion was not associated with worsened steatosis. The authors observed that deletion of Phd1-3, which increased HIF2 $\alpha$ stabilisation still further, did worsen steatosis, suggesting that lower level HIF $2 \alpha$ activation may be predominantly beneficial via improved insulin sensitivity, while higher levels of stabilisation, as occurs with Phd1-3 and $V h l$ deletion (and potentially in long-term NAFLD) has a detrimental effect due to inhibition of FAO, leading to worsened steatosis.

Overall, significant evidence points toward a steatosispromoting role for chronic HIF2 $\alpha$ activation in liver, likely occurring via inhibition of FAO and upregulation of lipogenesis, though studies investigating the effect of Hif $2 a$ deletion in NAFLD on FAO are needed to confirm this. Meanwhile, low levels of HIF $2 \alpha$ activation in metabolic diseases appear to have a beneficial effect on insulin sensitivity and glucose handling. Whether HIF1 $\alpha$ activation is protective or harmful in the context of metabolic disease and hepatic steatosis remains less clear. There are conflicting results which may be the result of opposing roles in different cell types and tissues, although in hepatocytes specifically, HIF $1 \alpha$ activation in obesity appears to improve insulin 


\section{A Hepatocytes}

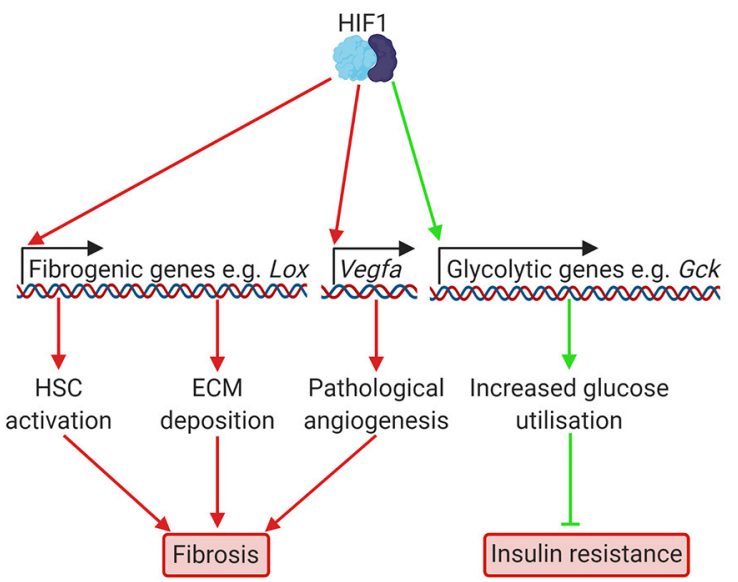

\section{B Macrophages}

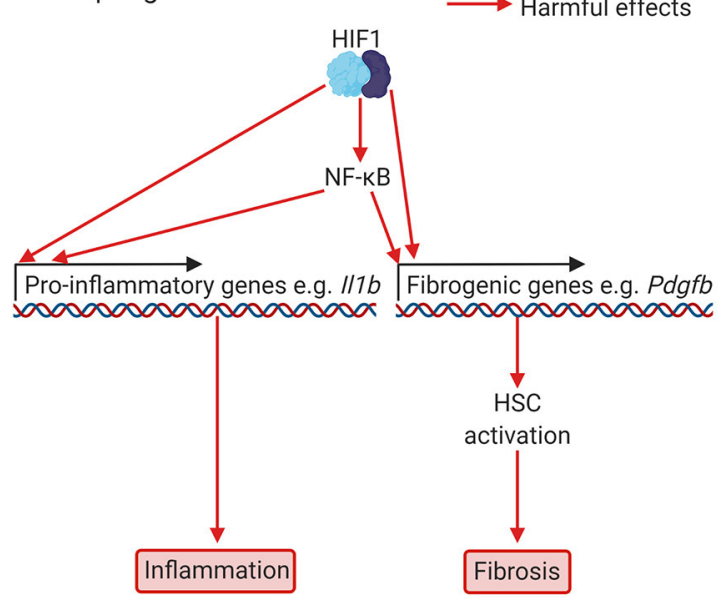

\section{c Hepatic Stellate Cells}

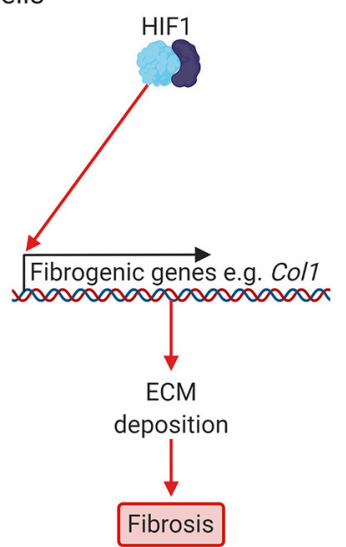

FIGURE 3 | Putatively beneficial and harmful effects of HIF1 activation in NAFLD and NASH. (A) In hepatocytes, HIF1 activation leads to increased expression of fibrogenic genes, including genes responsible for HSC activation (e.g., Pdgfb), ECM deposition (e.g., Lox), and pathological angiogenesis (Vegfa). Pathological angiogenesis has only been investigated in fibrosis models, not NAFLD models. HIF activation also increases expression of glycolytic genes such as glucokinase and glucose transporters, which increases glucose consumption and improves glucose handling. This can help prevent insulin resistance. (B) In macrophages, including resident macrophages in the liver, Kupffer cells, HIF1 activation increases expression of pro-inflammatory cytokines such as II1b, leading to inflammation, and of fibrogenic genes, such as the HSC activator Pdgfb, leading to fibrosis. HIF1 also appears to activate NF-KB, a key regulator of fibrosis and inflammation. (C) In HSCs, which will be activated at increased levels due to signals from other cells resulting from HIF1 activation, HIF1 activation is also required for transcription of fibrogenic genes, such as Col1, encoding Type 1 Collagen. For many of these effects of HIF1 activation, the precise mechanisms are not yet clear and not all genes mentioned are necessarily under direct HIF1 control. Col1, Type 1 Collagen; Gck, glucokinase; ECM, extracellular matrix; HIF, hypoxia-inducible factor; HSC, hepatic stellate cell; I1b, interleukin 1b; NF-кB, nuclear factor kappa-light-chain-enhancer of activated B cells; Pdgfb, platelet derived growth factor b; Vegfa, vascular endothelial growth factor $\mathrm{A}$.

sensitivity and may be required to maintain FAO and prevent increased lipogenesis.

\section{HIFs and Fibrosis in NAFLD and NASH}

Fibrosis is a key component of NAFLD in its most severe forms (51) and can occur both in patients of non-inflammatory non-alcoholic fatty liver and of inflammatory NASH (52). It is associated with worse outcomes and higher mortality rates in patients with NAFLD $(53,54)$. HIF-signalling likely contributes to fibrosis in NAFLD as shown by studies of fibrosis in general, and of fibrosis in NAFLD in particular. Liver hypoxia has been demonstrated in animal models of fibrotic and cirrhotic liver disease (see Table 1 for an overview of fibrosis, cirrhosis, and NAFLD models), including in diethylnitrosamine cirrhosis (72), $\mathrm{CCl}_{4}$ induced fibrosis (73), bile duct ligation (BDL) (74), and high dietary trans-fat induced NAFLD (56), and increased levels of HIF $1 \alpha$ have been found in mouse models (75) and patients with fibrotic liver disease (76). Deletion of Hifla protects against liver fibrosis in mouse models of both fibrotic liver disease, such as mice subjected to BDL (74), and models of NAFLD 
TABLE 1 | Rodent models for the study of NAFLD.

\begin{tabular}{|c|c|c|c|}
\hline Disease & Model & Aspects of NAFLD/NASH captured & References \\
\hline \multirow[t]{4}{*}{ NAFLD } & High fat diet with varying fat content & $\begin{array}{l}\text { Obesity, hepatic steatosis, often insulin resistance, sometimes liver } \\
\text { fibrosis, inflammation }\end{array}$ & $(17,30)$ \\
\hline & ob/ob mouse & Obesity, steatosis, mild fibrosis & $(55)$ \\
\hline & $d b / d b$ mouse & Obesity, insulin resistance, steatosis, mild fibrosis & $(55)$ \\
\hline & High trans-fat diet & Obesity, with steatosis, fibrosis and some inflammation & $(56)$ \\
\hline \multirow[t]{5}{*}{ NASH } & $\begin{array}{l}\text { Gubra-Amylin-NASH diet (high fat, high } \\
\text { fructose, high cholesterol) }\end{array}$ & $\begin{array}{l}\text { Obesity, severe steatosis, moderate inflammation, moderate } \\
\text { fibrosis }\end{array}$ & $(57)$ \\
\hline & ob/ob mouse with high calorie feeding & $\begin{array}{l}\text { Obesity, steatosis, moderate fibrosis, inflammation, moderate } \\
\text { fibrosis }\end{array}$ & $(55)$ \\
\hline & $d b / d b$ mouse with high calorie feeding & Obesity, insulin resistance & $(55)$ \\
\hline & Choline-deficient, L-amino acid-defined diet & No obesity, steatohepatitis and fibrosis & (3) \\
\hline & Methionine/choline deficient diet & No obesity, steatohepatitis and fibrosis & $(3,58)$ \\
\hline \multirow{2}{*}{$\begin{array}{l}\text { Cholestatic, } \\
\text { fibrotic liver } \\
\text { disease }\end{array}$} & Bile duct ligation & Liver fibrosis & $(59)$ \\
\hline & Repeated $\mathrm{CCl}_{4}$ injection & Liver fibrosis & $(60-62)$ \\
\hline $\begin{array}{l}\text { Cirrhotic liver } \\
\text { disease }\end{array}$ & Diethylnitrosamine injection/feeding & Severe liver injury and cirrhosis, can induce hepatocarcinoma & $(63)$ \\
\hline
\end{tabular}

TABLE 2 | Relevant in vitro and in vivo models of chronic and chronic intermittent hypoxia.

\begin{tabular}{|c|c|c|c|}
\hline System & Model & Details of model & References \\
\hline \multirow[t]{3}{*}{ in vitro } & Cells cultured in hypoxic chambers & $\begin{array}{l}\text { Constant hypoxia achieved using high levels of nitrogen. Range } \\
\text { oxygen concentrations can be used, } 1 \% \text { most common. Wide } \\
\text { range of timeframes. }\end{array}$ & $(64,65)$ \\
\hline & Cells treated with cobalt chloride & $\begin{array}{l}\text { Model of HIF activation similar to constant hypoxia. Cellular } \\
\text { response sometimes differs from true hypoxia. }\end{array}$ & $(65,66)$ \\
\hline & $\begin{array}{l}\text { Cells cultured in hypoxic chambers with cycling } \\
\text { oxygen levels }\end{array}$ & $\begin{array}{l}\text { Models } \mathrm{ClH} \text { in vitro. Wide range of oxygen levels at nadir and cycle } \\
\text { patterns in use. }\end{array}$ & $(65)$ \\
\hline \multirow[t]{3}{*}{ in vivo } & Rodents in hypoxic chambers & $\begin{array}{l}\text { Constant hypoxia achieved using high levels of nitrogen. Range of } \\
\text { oxygen concentrations in use. }\end{array}$ & $(67,68)$ \\
\hline & $\begin{array}{l}\text { Rodents in hypoxic chambers with cycling } \\
\text { oxygen levels }\end{array}$ & $\begin{array}{l}\text { Chronic intermittent hypoxia to model OSA. Oxygen cycles often } \\
\text { applied only during sleeping hours of rodents. Wide range of } \\
\text { oxygen levels at nadir and cycle patterns in use. }\end{array}$ & $(39,69)$ \\
\hline & Rodents injected with sodium nitrite & Chronic intermittent hypoxemia through methemoglobinemia. & $(70,71)$ \\
\hline
\end{tabular}

$(56,77)$. Similarly, hepatocyte-specific deletion of $V h l$, which increases both HIF1 $\alpha$ and HIF2 $\alpha$ signalling led to fibrosis which was normalised by Hif2a (but not Hifla) deletion (34), and hepatocyte-specific deletion of Hif2a protects against fibrosis in mouse models of NAFLD (3). It therefore appears likely that HIF-signalling contributes to liver fibrosis in NAFLD. HIFsignalling may be involved in fibrosis via several mechanisms, including regulation of the expression of fibrogenic mediators in hepatocytes, Kupffer cells (resident macrophages in the liver) and hepatic stellate cells (HSCs) (see Figure 3), and by contributing to aberrant angiogenesis, a process that occurs in parallel with fibrosis and appears to be mechanistically linked to it (78).

HIF regulated expression of fibrogenic mediators in hepatocytes has been demonstrated in several relevant in vitro and in vivo models. Isolated mouse hepatocytes exposed to hypoxia show increased expression of plasminogen activatorinhibitor 1 (PAI-1), and this is partially prevented by Hifla deletion and completely prevented by Hiflb deletion, suggesting both HIF1 $\alpha$ and HIF2 $\alpha$ may be involved (79) (Figures 2, 3). PAI-1 contributes to fibrosis by inhibiting the activities of matrix metalloproteinases, leading to excessive collagen and extracellular matrix (ECM) accumulation (80). Similarly, AML12 mouse hepatocyte cells exposed to hypoxia (81), and HepG2 cells treated with the HIF stabiliser cobalt chloride and free fatty acids (66) show increased expression of genes encoding pro-fibrotic proteins, such as Type 1 Collagen $\alpha$ (COL1A1) and $\alpha$-smooth muscle actin ( $\alpha$-SMA). In NAFLD models (Table 1), hepatocytespecific deletion of Hifla protects against collagen deposition and suppresses collagen crosslinking in the media of isolated hepatocytes exposed to hypoxia (56). This is likely to be due to decreased lysyl oxidase (Lox) expression, which requires Hifla 
in vitro (56). Lox expression has also been shown by chromatin immunoprecipitation to be under the control of HIF $2 \alpha$ (34). In another study of NAFLD models, hepatocyte-specific deletion of Hifla decreased collagen deposition and $\alpha$ smooth muscle actin staining (77). HepG2 cells treated with palmitic acid also showed increased HIF1 $\alpha$ levels, and increased Type I Collagen and fibronectin expression, which was prevented by treatment with Hifla siRNA (77). Further, hepatocyte-specific deletion of Hif $2 a$ protected against fibrosis in choline deficient, amino acid defined diet fed mice, a model of lean NAFLD (3). This was associated with lower levels of Col1 (Collagen I) and Acta2 ( $\alpha \mathrm{SMA})$ mRNA. Collectively, these studies highlight that one role of HIF activation in liver fibrosis is the direct regulation of fibrogenic genes in hepatocytes and that this likely occurs in NAFLD. However, hepatocytes are not considered major sources of ECM deposition in vivo, and so it remains unclear how central this mechanism is to the pathology of NAFLD.

HSCs are the main source of myofibroblasts and therefore fibrosis in liver disease. Myofibroblasts form in the injured liver in response to fibrogenic signals and are the major source of ECM deposition in fibrosis. They are not found in the healthy liver (82). Hypoxia and HIF-signalling appear to play an important role in the activation of HSCs and in regulating the expression of fibrogenic mediators in HSCs. Hypoxia increases the expression of Type I collagen in activated HSCs (72) and HIF-signalling is required for the expression of collagen synthesis genes in isolated HSCs (83) and the production of HSC activators (including platelet derived growth factor (PDGF)-B) in livers in BDL (74), which suggests hypoxia signalling in hepatocytes may play an important role in activating HSCs. Further evidence for this comes from in vitro studies; HIF signalling is required for the upregulation of HSC activators in isolated mouse hepatocytes exposed to hypoxia (79), and the conditioned medium of AML12 cells exposed to hypoxia induces $\alpha$-SMA expression in HSC-T6 cells (81). Similarly, extracellular vesicles isolated from HepG2 cells treated with fatty acids and cobalt chloride to stabilise HIFs induced the expression of fibrotic genes such as Collagen1 and $\alpha$-SMA in the human HSC LX2 cell line (66). HSCs are also activated by Kupffer cells and isolated Kupffer cells exposed to hypoxia show increased PDGF-B expression (84). This is normalised by Hiflb deletion (84) and myeloid specific deletion of Hifla or $b$ protects against fibrosis in BDL (85). Overall, evidence suggests that HIF-signalling is involved in HSC activation by acting directly in HSCs to increase expression of fibrogenic mediators, as well as by increasing the expression of signalling factors that activate HSCs in hepatocytes and Kupffer cells, though this has not been investigated in the context of NAFLD in vivo and the relative importance of HIF1 and HIF2 remains unclear.

A further important mechanism linking fibrosis and HIFsignalling is pathological angiogenesis; a common feature of fibrosis and cirrhosis that appears to be closely linked to fibrosis (78). Physiologically, angiogenesis is an important feature of the adaptive response to hypoxia, and is especially vital in liver regeneration after injury, to enable blood supply to regrowing liver regions. It is largely driven by HIF1 $\alpha$-mediated expression of VEGF and treatment with the PHD inhibitor
DMOG increases the speed of liver regeneration in rats after portal vein ligation and parenchymal transection, and portal vein ligation alone (86). In pathological or aberrant angiogenesis however, immature neovessels form, which are incapable of resolving localised hypoxia in liver disease, and may lead to chronic HIF activation. Aberrant angiogenesis is likely mediated by increased VEGF expression in fibrosis due to activated HIF signalling (72). Anti-angiogenic treatment with VEGF neutralising antibodies or the VEGF Receptor 2 inhibitor sorafenib can prevent fibrosis in BDL models of liver fibrosis $(87,88)$, although VEGF may also play a role in fibrosis resolution (88). VEGF expression is increased in hypoxic hepatocytes in a HIF1 $\alpha$-dependent manner (79) and in hypoxic Kupffer cells in a HIF1 $\beta$-dependent manner (84). VEGF-signalling is highly active in HSCs from areas of active fibrogenesis in patients and animal models, and VEGF stimulates HSC chemotaxis (89). T6-HSCs exposed to hypoxia have reduced levels of VHL, resulting in increased HIF1 $\alpha$ and VEGF expression, which is normalised by cyclooxygenase 2 inhibition (90). Thus, chronic HIF-activation may contribute to fibrosis by upregulating VEGF, which contributes to HSC activation and leads to aberrant angiogenesis. However, this has only been investigated in models of fibrotic liver disease, rather than non-alcoholic or metabolic associated fatty liver disease, and further work is required to determine whether pathological angiogenesis is also involved in these conditions.

Hypoxia signalling may also be linked to fibrosis via interaction with nuclear factor (NF)- $\mathrm{B}$ signalling. NF- $\kappa \mathrm{B}$ is thought to be an important driver of fibrosis and inflammation in NAFLD (91) and inactivation of NF- $\kappa$ B, in particular in Kupffer cells, protects against fibrosis in mice injected with $\mathrm{CCl}_{4}(60)$. NF- $\kappa \mathrm{B}$ signalling is also activated in HSCs and myofibroblasts in the livers of $\mathrm{CCl}_{4}$ and $\mathrm{BDL}$ rodent models, and human patients of fibrotic liver disease (92). There is considerable evidence of crosstalk between NF- $\kappa \mathrm{B}$ and HIF signalling $(93,94)$, particularly in immune cells $(95)$. However, the specific link between HIF and NF- $\kappa$ B signalling in the context of NAFLD remains less clear. While it has been demonstrated that both HIF $2 \alpha$ and NF- $\kappa$ B accumulate in the livers of patients with NASH and mice exposed to hypoxia (96), it is unclear whether their respective signalling pathways interact and whether modulation of either can affect the other, and thereby improve fibrosis.

A link between OSA and liver fibrosis in NAFLD also appears likely. In patients with OSA and obesity, more severe OSA was associated with worsened fibrosis (29), and circulating levels of LOX (which is regulated by HIFs) are higher in patients with obesity and more severe OSA (64). In mice fed a high trans-fat diet and exposed to $\mathrm{CIH}$ (97), and in rats fed a HFD to induce $\mathrm{NASH}$ and injected with sodium nitrite to mimic CIH (70) fibrosis worsened. It is not clear what mechanisms contributed to this. In the NASH rat model (70), sodium nitrite injection was associated with increased HIF1 $\alpha$, VEGFA and VEGF receptor 2 levels. Silencing of HIF1 $\alpha$, however, normalised VEGFA and VEGF receptor 2 levels and improved fibrosis, suggesting pathological angiogenesis driven by HIF1 $\alpha$ signalling may play a role. VEGF receptor neutralising antibodies attenuated the 
development of fibrosis in $\mathrm{CCl}_{4}$ induced fibrosis, and VEGF stimulated HSC proliferation in vitro (98), further supporting a role for pathological angiogenesis. However, the link between $\mathrm{CIH}$ and fibrosis may not always be HIF1 $\alpha$ mediated, as, while HIF1 $\alpha$ deletion improved liver fibrosis and inflammation in trans-fat diet fed mice with or without $\mathrm{CIH}$, it did so without significant interaction with $\mathrm{CIH}$ effects (97). Further research is needed to understand the mechanisms involved in the link between CIH/OSA and liver fibrosis.

\section{HIFs and Inflammation in NAFLD and NASH}

Hypoxia is a common feature of chronically-inflamed tissue, and, as highlighted by a number of recent reviews (99-102), HIFs play important roles in inflammation and immunity, including via the activation of macrophages and certain types of $\mathrm{T}$ cells, and regulation of inflammatory cytokine expression, partly mediated via crosstalk with NF- $\kappa \mathrm{B}$ signalling (103). Current evidence suggests that both HIF1 $\alpha$ and HIF $2 \alpha$ play a harmful role in NASH (Figures 2, 3), a more severe form of NAFLD with marked liver inflammation (104). This involves hepatocytespecific and immune cell-specific roles of HIFs. Hepatocytespecific normoxic activation of HIF $1 \alpha$ and HIF $2 \alpha$ via deletion of $\mathrm{Vhl}$ worsens lipid accumulation, fibrosis and inflammation, with global microarray expression analysis showing increased expression of proinflammatory cytokines (34). This pathological phenotype was averted by concomitant deletion of Hif $2 a$, but not Hif1a, suggesting a greater importance for HIF2 $\alpha$ in driving steatohepatitis in hepatocytes. Similarly, in patients with NAFLD, hepatic levels of HIF2 $\alpha$ and HIF $1 \alpha$ are increased in early, noninflamed stages of NAFLD, but only HIF $2 \alpha$ levels are further increased in the livers of patients with NASH vs. patients with non-inflamed NAFLD (40), though studies in animal models do suggest a possible role for HIF1 $\alpha$ as well (97).

In $\mathrm{NASH}$, treatment studies and genetic interference with the HIF pathway point toward HIF activation contributing to inflammation. Treatment with the cardiac glycoside digoxin suppressed HIF1 $\alpha$ pathway activation and decreased neutrophil and monocyte infiltration, as well as liver damage, in a mouse model of NASH (105). Further, HIF1 $\alpha$ was increased in macrophages from patients and a mouse model of NASH (106). Myeloid specific HIF1 $\alpha$ stabilisation worsened steatosis and inflammation, with increased macrophage infiltration in the liver, higher expression of the proinflammatory cytokines macrophage chemoattractant protein 1 (MCP1) and interleukin (IL)-1b in liver macrophages, and higher hepatic levels of $M c p 1$ and tumour necrosis factor $\alpha$ (Tnfa) mRNA. Palmitic acid treatment also induced HIF1 $\alpha$ in macrophages in vitro, and silencing of Hifla suppressed the activation of NF- $\kappa \mathrm{B}$ (106). HIF $2 \alpha$, which is also increased in patients and mouse models of NASH, appears to influence liver inflammation via control of hepatocyte production of the cytokine histidine rich glycoprotein (HRGP) (3). HRGP induces a proinflammatory $\mathrm{M} 1$ phenotype in macrophages, and deletion protects against NASH in methionine-choline deficient diet fed mice (107). Choline-deficient, amino acid-defined diet feeding, another model of NASH, increased levels of HRGP and other proinflammatory cytokines (including $\mathrm{TNF} \alpha$ ) in mouse livers. This was prevented by Hif $2 a$ deletion, whilst overexpression of Hif $2 \alpha$ increased HRGP levels in HepG 2 cells (3). It therefore appears that both HIF $1 \alpha$ and HIF $2 \alpha$ contribute to inflammation in NASH, and that this involves HIF-mediated mechanisms in several cell types, especially hepatocytes and macrophages. How these mechanisms function is not entirely clear, however.

HIF-signalling may also be involved in the link between OSA and NAFLD progression generally, and regarding inflammation in particular. Severity of nocturnal hypoxia in OSA correlates with NAFLD/NASH severity, including liver inflammation, independent of other risk factors in patients (25), and subjecting mice to $\mathrm{CIH}$ in order to mimic OSA leads to increased liver HIF $1 \alpha, T N F \alpha$, and NF- $\kappa$ B (108). OSA induced inflammation may be mediated in part by changes in the balance between anti-inflammatory regulatory $\mathrm{T}$ cells and pro-inflammatory Th17 helper $\mathrm{T}$ cells (109). In mice fed a HFD, this ratio was shifted toward the pro-inflammatory Th17 cells, and this shift was even greater when $\mathrm{CIH}$ was superimposed through injection of sodium nitrite. Interference of HIF $1 \alpha$ partially normalised this shift in the $\mathrm{CIH}$ and HFD exposed mice, and in hypoxic T-cells in vitro. This suggests HIF signalling in patients with NAFLD/NASH and OSA may induce or worsen inflammation, though more studies are needed to confirm this.

\section{OPEN QUESTIONS}

The evidence currently available highlights potential mechanisms by which HIF signalling may be involved in several key aspects of NAFLD, namely steatosis, inflammation and fibrosis. Further work is required to confirm many of these mechanisms and provide a more detailed understanding, and to determine whether targeting HIF signalling is a viable treatment strategy to improve these aspects of the pathology. It also remains uncertain what drives liver hypoxia and HIF activation in NAFLD in the first place.

While high fat feeding has been shown to induce liver hypoxia even in a relatively short time frame (10), it has not yet been determined what processes lead to this. It also remains unclear whether ROS production plays a role in HIF induction in NAFLD. Short-term feeding of NAFLD inducing diets combined with measurement of oxidative metabolism [e.g., using mitochondrial respirometry (110) or metabolomics, especially with isotope tracing $(111,112)]$ in the liver could elucidate whether development of liver hypoxia is preceded by increased oxygen consumption. Concomitantly, measurement of ROS markers [such as thiol (113) or lipid peroxidation (114)] could show whether ROS production is likely to play a role in HIF activation, which could be followed up with in vitro studies using ROS scavengers to investigate whether this prevents HIF activation in in vitro models of NAFLD. Investigation of SIRT4 in this context could also be valuable as reduced levels of this sirtuin have been demonstrated in patients with NAFLD (19) and it has been proposed that this may be a driver of increased ROS production in this disease. 
It has been demonstrated that HIF $2 \alpha$ activation in normoxia can limit FAO in hepatocytes (32). However, as demonstrated by the observation that lipogenic gene expression is decreased in mice with HIF $2 \alpha$ activation due to $V h l$ disruption (32), while it is increased in NAFLD rodent models (9) [which also show HIF $2 \alpha$ activation (3)], this does not necessarily mean that HIF $2 \alpha$ in NAFLD also reduces FAO. Studies that investigate the function and expression of enzymes involved in FAO, and of the key cellular organelle in oxidative metabolism, the mitochondrion, in NAFLD models (with HIF2 $\alpha$ deletion or pharmacological inhibition) and patients would help elucidate this. More detailed metabolomic studies in these settings may also provide further insight into how HIF2 $\alpha$ activation affects metabolism in NAFLD.

In many cases, details of the signalling pathways by which HIF activation contributes to NAFLD and NASH remain unclear. This includes the pathways leading to increased expression of lipogenic, fibrogenic, and pro-inflammatory genes. Biochemical and molecular biology techniques such as chromatin immunoprecipitation and co-immunoprecipitation may provide targets for further investigation. In vitro studies may prove useful to probe these targets due to the greater ease of deletion and overexpression of genes. However, the current lack of consistent in vitro NAFLD models may make this more challenging.

Currently, it is unclear to what extent OSA is required for HIF activation in patients with NAFLD, and whether HIF activation resulting from OSA differs in its effects on NAFLD from HIF activation without OSA. This is likely to be the case due to the hypoxia-reoxygenation cycles inherent to OSA, which may affect activation of HIFs (e.g., by favouring HIF $1 \alpha$ over HIF $2 \alpha$ activation) and other co-activated pathways. Further investigations into how closely linked HIF activation and OSA are in patients with NAFLD would be useful, and studies in animal models of NAFLD exposed to CIH-a way of mimicking OSA in rodents, which do not develop OSA spontaneously-could provide insight into whether and how these pathophysiological mechanisms differ.

The ultimate goal of understanding the involvement of HIF signalling in NAFLD would be to attempt to treat the disease by targeting this pathway. Current evidence supports the use of animal studies to investigate this, and both HIF $1 \alpha$ and HIF $2 \alpha$ antagonists have been developed, largely with a view to treating cancers (8). Early studies, looking for example at the effect of HIF $2 \alpha$ antagonism in HFD induced hepatosteatosis in mice have shown promising results (9), but studies in more severe models of NAFLD and NASH do still need be conducted.

Finally, while this review has focussed on the role of HIF signalling in the liver, some studies point toward roles of HIFs in other tissues and organs that are likely to impact on NAFLD and outcomes in NAFLD. For example, HIF activation in adipocytes (115) and adipose tissue macrophages (116) has been shown to affect insulin resistance, which is likely to affect NAFLD development. Further, the close links between gut and liver are likely to be involved in NAFLD, as shown by the association between inflammatory bowel disease and NAFLD (117). HIFs are known to play an important role in inflammation in the intestine (118) and may be an important part of this inter-organ link. Indeed, HIF activation in the intestine can affect NAFLD directly (119). The role of HIFs in other organs in the broader context of metabolic disease has recently been reviewed elsewhere (120), and better understanding of this, and how it may affect interactions between other organs and the liver is likely to aid in the development of therapeutic strategies for NAFLD.

\section{CONCLUSION}

In conclusion, considerable evidence points toward HIF activation occurring in NAFLD and NASH, and having widespread, predominantly harmful effects. Both HIF1 $\alpha$ and HIF $2 \alpha$ activation appear to worsen inflammation, though the mechanisms involved in this require further study. Further, evidence from studies of fibrosis shows important HIF mediated mechanisms, including control of profibrotic gene expression in hepatocytes and HSCs, regulation of HSC activation and HIF mediated pathological angiogenesis, though only control of profibrotic gene expression has been demonstrated to occur in animal models of NAFLD and NASH. Evidence also highlights a role for HIFs, in particular HIF $2 \alpha$, in driving steatosis. Studies of HIF activation under normoxic conditions suggest that HIF $2 \alpha$ can inhibit FAO, while studies that interfere with HIF2 $\alpha$ activation in NAFLD via oxygen therapy or antagonism suggest that HIF $2 \alpha$ drives lipogenesis. These mechanisms could explain the protective effect that Hif $2 \alpha$ deletion has against steatosis in NAFLD. While some beneficial effects of HIF activation have been noted, such as a potential role in improving insulin sensitivity, on balance, HIF activation appears to be harmful in NAFLD, and may therefore be a useful therapeutic target. Further research is required to fully elucidate the mechanisms by which HIF activation contributes to NAFLD and NASH, in particular the effect on FAO, the signalling pathways involved in regulating the expression of lipogenic, fibrogenic, and pro-inflammatory genes, and the link between HIF signalling and OSA in NAFLD and NASH.

\section{AUTHOR CONTRIBUTIONS}

All authors listed have made a substantial, direct and intellectual contribution to the work, and approved it for publication.

\section{FUNDING}

LH was supported by a 4-year PhD studentship Program funded by the Wellcome Trust (Grant Number: 220033/Z/19/Z). AM was supported by the Research Councils UK (Grant Number: EP/E500552/1).

\section{ACKNOWLEDGMENTS}

The authors thank Alice Sowton for her critical appraisal of the manuscript. Figures were created with BioRender.com. 


\section{REFERENCES}

1. Younossi ZM. Non-alcoholic fatty liver disease - a global public health perspective. J Hepatol. (2019) 70:531-44. doi: 10.1016/j.jhep.2018.10.033

2. Calzadilla Bertot L, Adams LA. The natural course of non-alcoholic fatty liver disease. Int J Mol Sci. (2016) 17:774. doi: 10.3390/ijms17050774

3. Morello E, Sutti S, Foglia B, Novo E, Cannito S, Bocca C, et al. Hypoxiainducible factor 2alpha drives nonalcoholic fatty liver progression by triggering hepatocyte release of histidine-rich glycoprotein. Hepatology. (2018) 67:2196-214. doi: 10.1002/hep.29754

4. Duan C. Hypoxia-inducible factor 3 biology: complexities and emerging themes. Am J Physiol Cell Physiol. (2016) 310:C2609. doi: 10.1152/ajpcell.00315.2015

5. Kaelin WG, Jr., Ratcliffe PJ. Oxygen sensing by metazoans: the central role of the HIF hydroxylase pathway. Mol Cell. (2008) 30:393-402. doi: 10.1016/j.molcel.2008.04.009

6. Dengler VL, Galbraith M, Espinosa JM. Transcriptional regulation by hypoxia inducible factors. Crit Rev Biochem Mol Biol. (2014) 49:115. doi: 10.3109/10409238.2013.838205

7. Lee JW, Ko J, Ju C, Eltzschig HK. Hypoxia signaling in human diseases and therapeutic targets. Exp Mol Med. (2019) 51:1-13. doi: 10.1038/s12276-019-0235-1

8. Yu T, Tang B, Sun X. Development of inhibitors targeting hypoxiainducible factor 1 and 2 for cancer therapy. Yonsei Med J. (2017) 58:48996. doi: 10.3349/ymj.2017.58.3.489

9. Feng Z, Zou X, Chen Y, Wang H, Duan Y, Bruick RK. Modulation of HIF2alpha PAS-B domain contributes to physiological responses. Proc Natl Acad Sci USA. (2018) 115:13240-5. doi: 10.1073/pnas.1810897115

10. Zhang $\mathrm{X}$, Huang $\mathrm{C}, \mathrm{Li} \mathrm{X}$, Shangguan $\mathrm{Z}$, Wei $\mathrm{W}$, Liu $\mathrm{S}$, et al. HFD and HFD-provoked hepatic hypoxia act as reciprocal causation for NAFLD via HIF-independent signaling. BMC Gastroenterol. (2020) 20:366. doi: 10.1186/s12876-020-01515-5

11. Kietzmann T. Liver zonation in health and disease: hypoxia and hypoxiainducible transcription factors as concert masters. Int J Mol Sci. (2019) 20:2347. doi: 10.3390/ijms20092347

12. Mantena SK, Vaughn DP, Andringa KK, Eccleston HB, King AL, Abrams GA, et al. High fat diet induces dysregulation of hepatic oxygen gradients and mitochondrial function in vivo. Biochem J. (2009) 417:18393. doi: $10.1042 / \mathrm{BJ} 20080868$

13. Aguilera KY, Brekken RA. Hypoxia studies with pimonidazole in vivo. Bio Protoc. (2014) 4:e1254. doi: 10.21769/BioProtoc.1254

14. Carabelli J, Burgueno AL, Rosselli MS, Gianotti TF, Lago NR, Pirola CJ, et al. High fat diet-induced liver steatosis promotes an increase in liver mitochondrial biogenesis in response to hypoxia. J Cell Mol Med. (2011) 15:1329-38. doi: 10.1111/j.1582-4934.2010.01128.x

15. Simoes ICM, Janikiewicz J, Bauer J, Karkucinska-Wieckowska A, Kalinowski P, Dobrzyn A, et al. Fat and sugar-a dangerous duet. A comparative review on metabolic remodeling in rodent models of nonalcoholic fatty liver disease. Nutrients. (2019) 11. doi: 10.3390/nu11122871

16. Movafagh S, Crook S, Vo K. Regulation of hypoxia-inducible factor-1a by reactive oxygen species: new developments in an old debate. J Cell Biochem. (2015) 116:696-703. doi: 10.1002/jcb.25074

17. Vial G, Dubouchaud H, Couturier K, Cottet-Rousselle C, Taleux N, Athias A, et al. Effects of a high-fat diet on energy metabolism and ROS production in rat liver. J Hepatol. (2011) 54:348-56. doi: 10.1016/j.jhep.2010.06.044

18. Anavi S, Hahn-Obercyger M, Madar Z, Tirosh O. Mechanism for HIF-1 activation by cholesterol under normoxia: a redox signaling pathway for liver damage. Free Radic Biol Med. (2014) 71:61-9. doi: 10.1016/j.freeradbiomed.2014.03.007

19. Tarantino G, Finelli C, Scopacasa F, Pasanisi F, Contaldo F, Capone D, et al. Circulating levels of sirtuin 4, a potential marker of oxidative metabolism, related to coronary artery disease in obese patients suffering from NAFLD, with normal or slightly increased liver enzymes. Oxid Med Cell Longev. (2014) 2014:920676. doi: 10.1155/2014/920676

20. Selak MA, Armour SM, MacKenzie ED, Boulahbel H, Watson DG, Mansfield KD, et al. Succinate links TCA cycle dysfunction to oncogenesis by inhibiting HIF-alpha prolyl hydroxylase. Cancer Cell. (2005) 7:7785. doi: $10.1016 /$ j.ccr.2004.11.022
21. Joo HY, Yun M, Jeong J, Park ER, Shin HJ, Woo SR, et al. SIRT1 deacetylates and stabilizes hypoxia-inducible factor-1alpha (HIF-1alpha) via direct interactions during hypoxia. Biochem Biophys Res Commun. (2015) 462:294-300. doi: 10.1016/j.bbrc.2015.04.119

22. Wu T, Liu YH, Fu YC, Liu XM, Zhou XH. Direct evidence of sirtuin downregulation in the liver of non-alcoholic fatty liver disease patients. Ann Clin Lab Sci. (2014) 44:410-8.

23. Sforza E, Roche F. Chronic intermittent hypoxia and obstructive sleep apnea: an experimental and clinical approach. Hypoxia. (2016) 4:99108. doi: 10.2147/HP.S103091

24. Romero-Corral A, Caples SM, Lopez-Jimenez F, Somers VK. Interactions between obesity and obstructive sleep apnea: implications for treatment. Chest. (2010) 137:711-9. doi: 10.1378/chest.09-0360

25. Aron-Wisnewsky J, Minville C, Tordjman J, Levy P, Bouillot JL, Basdevant A, et al. Chronic intermittent hypoxia is a major trigger for nonalcoholic fatty liver disease in morbid obese. J Hepatol. (2012) 56:22533. doi: 10.1016/j.jhep.2011.04.022

26. Tarantino G, Citro V, Capone D. Nonalcoholic fatty liver disease: a challenge from mechanisms to therapy. J Clin Med. (2019) 9:15. doi: 10.3390/jcm9010015

27. Hu CJ, Wang LY, Chodosh LA, Keith B, Simon MC. Differential roles of hypoxia-inducible factor lalpha (HIF-1alpha) and HIF-2alpha in hypoxic gene regulation. Mol Cell Biol. (2003) 23:9361-74. doi: 10.1128/MCB.23.24.9361-9374.2003

28. Wu R, Chang HC, Khechaduri A, Chawla K, Tran M, Chai X, et al. Cardiacspecific ablation of ARNT leads to lipotoxicity and cardiomyopathy. J Clin Invest. (2014) 124:4795-806. doi: 10.1172/JCI76737

29. Polotsky VY, Patil SP, Savransky V, Laffan A, Fonti S, Frame LA, et al. Obstructive sleep apnea, insulin resistance, and steatohepatitis in severe obesity. Am J Respir Crit Care Med. (2009) 179:22834. doi: $10.1164 / \mathrm{rccm} .200804-608 \mathrm{OC}$

30. Ochiai D, Goda N, Hishiki T, Kanai M, Senoo-Matsuda N, Soga T, et al. Disruption of HIF-1alpha in hepatocytes impairs glucose metabolism in diet-induced obesity mice. Biochem Biophys Res Commun. (2011) 415:4459. doi: 10.1016/j.bbrc.2011.10.089

31. Bugianesi E, Moscatiello S, Ciaravella MF, Marchesini G. Insulin resistance in nonalcoholic fatty liver disease. Curr Pharm Des. (2010) 16:194151. doi: $10.2174 / 138161210791208875$

32. Rankin EB, Rha J, Selak MA, Unger TL, Keith B, Liu Q, et al. Hypoxiainducible factor 2 regulates hepatic lipid metabolism. Mol Cell Biol. (2009) 29:4527-38. doi: 10.1128/MCB.00200-09

33. Kucejova B, Sunny NE, Nguyen AD, Hallac R, Fu X, Pena-Llopis S, et al. Uncoupling hypoxia signaling from oxygen sensing in the liver results in hypoketotic hypoglycemic death. Oncogene. (2011) 30:214760. doi: $10.1038 /$ onc. 2010.587

34. Qu A, Taylor M, Xue X, Matsubara T, Metzger D, Chambon P, et al. Hypoxiainducible transcription factor 2alpha promotes steatohepatitis through augmenting lipid accumulation, inflammation, and fibrosis. Hepatology. (2011) 54:472-83. doi: 10.1002/hep.24400

35. Grygiel-Gorniak B. Peroxisome proliferator-activated receptors and their ligands: nutritional and clinical implications-a review. Nutr J. (2014) 13:17. doi: 10.1186/1475-2891-13-17

36. Mooli RGR, Rodriguez J, Takahashi S, Solanki S, Gonzalez FJ, Ramakrishnan SK, et al. Hypoxia via ERK signaling inhibits hepatic PPARalpha to promote fatty liver. Cell Mol Gastroenterol Hepatol. (2021) 12:58597. doi: 10.1016/j.jcmgh.2021.03.011

37. Cao R, Zhao X, Li S, Zhou H, Chen W, Ren L, et al. Hypoxia induces dysregulation of lipid metabolism in HepG2 cells via activation of HIF2alpha. Cell Physiol Biochem. (2014) 34:1427-41. doi: 10.1159/000366348

38. Liu Y, Ma Z, Zhao C, Wang Y, Wu G, Xiao J, et al. HIF-1alpha and HIF-2alpha are critically involved in hypoxia-induced lipid accumulation in hepatocytes through reducing PGC-1alpha-mediated fatty acid betaoxidation. Toxicol Lett. (2014) 226:117-23. doi: 10.1016/j.toxlet.2014. 01.033

39. Chen J, Chen J, Fu H, Li Y, Wang L, Luo S, et al. Hypoxia exacerbates nonalcoholic fatty liver disease via the HIF2alpha/PPARalpha pathway. Am J Physiol Endocrinol Metab. (2019) 317:E710-22. doi: 10.1152/ajpendo.00052.2019 
40. Yu L, Wang H, Han X, Liu H, Zhu D, Feng W, et al. Oxygen therapy alleviates hepatic steatosis by inhibiting hypoxia-inducible factor-2alpha. J Endocrinol. (2020) 246:57-67. doi: 10.1530/JOE-19-0555

41. Arai T, Tanaka M, Goda N. HIF-1-dependent lipin1 induction prevents excessive lipid accumulation in choline-deficient diet-induced fatty liver. Sci Rep. (2018) 8:14230. doi: 10.1038/s41598-018-32586-w

42. Donnelly KL, Smith CI, Schwarzenberg SJ, Jessurun J, Boldt MD, Parks EJ. Sources of fatty acids stored in liver and secreted via lipoproteins in patients with nonalcoholic fatty liver disease. J Clin Invest. (2005) 115:134351. doi: $10.1172 / J C I 23621$

43. Lambert JE, Ramos-Roman MA, Browning JD, Parks EJ. Increased de novo lipogenesis is a distinct characteristic of individuals with nonalcoholic fatty liver disease. Gastroenterology. (2014) 146:726-35. doi: 10.1053/j.gastro.2013.11.049

44. Beysen C, Schroeder P, Wu E, Brevard J, Ribadeneira M, Lu W, et al. Inhibition of fatty acid synthase with FT-4101 safely reduces hepatic de novo lipogenesis and steatosis in obese subjects with non-alcoholic fatty liver disease: results from two early-phase randomized trials. Diabetes Obes Metab. (2021) 23:700-10. doi: 10.1111/dom.14272

45. Rey E, Melendez-Rodriguez F, Maranon P, Gil-Valle M, Carrasco AG, TorresCapelli $\mathrm{M}$, et al. Hypoxia-inducible factor 2alpha drives hepatosteatosis through the fatty acid translocase CD36. Liver Int. (2020) 40:255367. doi: $10.1111 /$ liv. 14519

46. Rey E, Del Pozo-Maroto E, Maranon P, Beeler B, Garcia-Garcia Y, Landete $\mathrm{P}$, et al. Intrahepatic expression of fatty acid translocase CD36 is increased in obstructive sleep apnea. Front Med. (2020) 7:450. doi: $10.3389 /$ fmed.2020.00450

47. Li J, Grigoryev DN, Ye SQ, Thorne L, Schwartz AR, Smith PL, et al. Chronic intermittent hypoxia upregulates genes of lipid biosynthesis in obese mice. $J$ Appl Physiol. (2005) 99:1643-8. doi: 10.1152/japplphysiol.00522.2005

48. Shin MK, Drager LF, Yao Q, Bevans-Fonti S, Yoo DY, Jun JC, et al. Metabolic consequences of high-fat diet are attenuated by suppression of HIF-1alpha. PLoS ONE. (2012) 7:e46562. doi: 10.1371/journal.pone.0046562

49. Wei K, Piecewicz SM, McGinnis LM, Taniguchi CM, Wiegand SJ, Anderson $\mathrm{K}$, et al. A liver Hif-2alpha-Irs2 pathway sensitizes hepatic insulin signaling and is modulated by Vegf inhibition. Nat Med. (2013) 19:13317. doi: $10.1038 / \mathrm{nm} .3295$

50. Taniguchi CM, Finger EC, Krieg AJ, Wu C, Diep AN, LaGory EL, et al. Crosstalk between hypoxia and insulin signaling through Phd3 regulates hepatic glucose and lipid metabolism and ameliorates diabetes. Nat Med. (2013) 19:1325-30. doi: 10.1038/nm.3294

51. Rinella ME, Sanyal AJ. Management of NAFLD. a stage-based approach. Nat Rev Gastroenterol Hepatol. (2016) 13:196-205. doi: 10.1038/nrgastro.2016.3

52. Singh S, Allen AM, Wang Z, Prokop LJ, Murad MH, Loomba R. Fibrosis progression in nonalcoholic fatty liver vs nonalcoholic steatohepatitis: a systematic review and meta-analysis of paired-biopsy studies. Clin Gastroenterol Hepatol. (2015) 13:643-54 e1-9; quiz e39-40. doi: 10.1016/j.cgh.2014.04.014

53. Kim D, Kim WR, Kim HJ, Therneau TM. Association between noninvasive fibrosis markers and mortality among adults with nonalcoholic fatty liver disease in the United States. Hepatology. (2013) 57:1357-65. doi: 10.1002/hep.26156

54. Ekstedt M, Hagstrom H, Nasr P, Fredrikson M, Stal P, Kechagias S, et al. Fibrosis stage is the strongest predictor for disease-specific mortality in NAFLD after up to 33 years of follow-up. Hepatology. (2015) 61:154754. doi: 10.1002/hep.27368

55. Trak-Smayra V, Paradis V, Massart J, Nasser S, Jebara V, Fromenty B. Pathology of the liver in obese and diabetic ob/ob and $\mathrm{db} / \mathrm{db}$ mice fed a standard or high-calorie diet. Int J Exp Pathol. (2011) 92:41321. doi: 10.1111/j.1365-2613.2011.00793.x

56. Mesarwi OA, Shin MK, Bevans-Fonti S, Schlesinger C, Shaw J, Polotsky VY. Hepatocyte hypoxia inducible factor-1 mediates the development of liver fibrosis in a mouse model of nonalcoholic fatty liver disease. PLoS ONE. (2016) 11:e0168572. doi: 10.1371/journal.pone.0168572

57. Boland ML, Oro D, Tolbol KS, Thrane ST, Nielsen JC, Cohen TS, et al. Towards a standard diet-induced and biopsy-confirmed mouse model of non-alcoholic steatohepatitis: impact of dietary fat source. World $J$ Gastroenterol. (2019) 25:4904-20. doi: 10.3748/wjg.v25.i33.4904
58. Rinella ME, Green RM. The methionine-choline deficient dietary model of steatohepatitis does not exhibit insulin resistance. J Hepatol. (2004) 40:4751. doi: 10.1016/j.jhep.2003.09.020

59. Van Campenhout S, Van Vlierberghe H, Devisscher L. Common bile duct ligation as model for secondary biliary cirrhosis. Methods Mol Biol. (2019) 1981:237-47. doi: 10.1007/978-1-4939-9420-5_15

60. Son G, Iimuro Y, Seki E, Hirano T, Kaneda Y, Fujimoto J. Selective inactivation of NF-kappaB in the liver using NF-kappaB decoy suppresses CCl4-induced liver injury and fibrosis. Am J Physiol Gastrointest Liver Physiol. (2007) 293:G631-9. doi: 10.1152/ajpgi.00185.2007

61. Dong S, Chen QL, Song YN, Sun Y, Wei B, Li XY, et al. Mechanisms of CCl4induced liver fibrosis with combined transcriptomic and proteomic analysis. J Toxicol Sci. (2016) 41:561-72. doi: 10.2131/jts.41.561

62. Scholten D, Trebicka J, Liedtke C, Weiskirchen R. The carbon tetrachloride model in mice. Lab Anim. (2015) 49:4-11. doi: 10.1177/0023677215571192

63. Tolba R, Kraus T, Liedtke C, Schwarz M, Weiskirchen R. Diethylnitrosamine (DEN)-induced carcinogenic liver injury in mice. Lab Anim. (2015) 49:5969. doi: $10.1177 / 0023677215570086$

64. Mesarwi OA, Shin MK, Drager LF, Bevans-Fonti S, Jun JC, Putcha N, et al. Lysyl oxidase as a serum biomarker of liver fibrosis in patients with severe obesity and obstructive sleep apnea. Sleep. (2015) 38:158391. doi: 10.5665/sleep.5052

65. Pavlacky J, Polak J. Technical feasibility and physiological relevance of hypoxic cell culture models. Front Endocrinol. (2020) 11:57. doi: 10.3389/fendo.2020.00057

66. Hernandez A, Reyes D, Geng Y, Arab JP, Cabrera D, Sepulveda $\mathrm{R}$, et al. Extracellular vesicles derived from fat-laden hepatocytes undergoing chemical hypoxia promote a pro-fibrotic phenotype in hepatic stellate cells. Biochim Biophys Acta Mol Basis Dis. (2020) 1866:165857. doi: 10.1016/j.bbadis.2020.165857

67. Jusman SW, Halim A, Wanandi SI, Sadikin M. Expression of hypoxiainducible factor-1alpha (HIF-1alpha) related to oxidative stress in liver of rat-induced by systemic chronic normobaric hypoxia. Acta Med Indones. (2010) 42:17-23.

68. Dukhande VV, Sharma GC, Lai JC, Farahani R. Chronic hypoxia-induced alterations of key enzymes of glucose oxidative metabolism in developing mouse liver are mTOR dependent. Mol Cell Biochem. (2011) 357:189-97. doi: 10.1007/s11010-0110889-z

69. Chopra S, Polotsky VY, Jun JC. Sleep apnea research in animals. Past, present, and future. Am J Respir Cell Mol Biol. (2016) 54:299-305. doi: 10.1165/rcmb.20150218TR

70. Wu W, Li W, Wei J, Wang C, Yao Y, Zhu W, et al. Chronic intermittent hypoxia accelerates liver fibrosis in rats with combined hypoxia and nonalcoholic steatohepatitis via angiogenesis rather than endoplasmic reticulum stress. Acta Biochim Biophys Sin. (2019) 51:15967. doi: $10.1093 /$ abbs/gmy169

71. Takayama F, Egashira T, Kawasaki H, Mankura M, Nakamoto $\mathrm{K}$, Okada S, et al. A novel animal model of nonalcoholic steatohepatitis (NASH): hypoxemia enhances the development of NASH. J Clin Biochem Nutr. (2009) 45:335-40. doi: 10.3164/jcb n. $09-29$

72. Corpechot C, Barbu V, Wendum D, Kinnman N, Rey C, Poupon R, et al. Hypoxia-induced VEGF and collagen I expressions are associated with angiogenesis and fibrogenesis in experimental cirrhosis. Hepatology. (2002) 35:1010-21. doi: 10.1053/jhep.2002.32524

73. Tugues S, Fernandez-Varo G, Munoz-Luque J, Ros J, Arroyo V, Rodes J, et al. Antiangiogenic treatment with sunitinib ameliorates inflammatory infiltrate, fibrosis, and portal pressure in cirrhotic rats. Hepatology. (2007) 46:1919-26. doi: 10.1002/hep.21921

74. Moon JO, Welch TP, Gonzalez FJ, Copple BL. Reduced liver fibrosis in hypoxia-inducible factor-1alpha-deficient mice. Am J Physiol Gastrointest Liver Physiol. (2009) 296:G582-92. doi: 10.1152/ajpgi.90368.2008

75. Moczydlowska J, Miltyk W, Hermanowicz A, Lebensztejn DM, Palka JA, Debek W. HIF-1 alpha as a key factor in bile duct ligation-induced liver fibrosis in rats. J Invest Surg. (2017) 30:41-6. doi: 10.1080/08941939.2016.1183734 
76. Wang J, Lu Z, Xu Z, Tian P, Miao H, Pan S, et al. Reduction of hepatic fibrosis by overexpression of von Hippel-Lindau protein in experimental models of chronic liver disease. Sci Rep. (2017) 7:41038. doi: 10.1038/srep41038

77. Han J, He Y, Zhao H, Xu X. Hypoxia inducible factor-1 promotes liver fibrosis in nonalcoholic fatty liver disease by activating PTEN/p65 signaling pathway. J Cell Biochem. (2019) 120:14735-44. doi: 10.1002/jcb.28734

78. Bocca C, Novo E, Miglietta A, Parola M. Angiogenesis and fibrogenesis in chronic liver diseases. Cell Mol Gastroenterol Hepatol. (2015) 1:47788. doi: 10.1016/j.jcmgh.2015.06.011

79. Copple BL, Bustamante JJ, Welch TP, Kim ND, Moon JO. Hypoxia-inducible factor-dependent production of profibrotic mediators by hypoxic hepatocytes. Liver Int. (2009) 29:101021. doi: 10.1111/j.1478-3231.2009.02015.x

80. Ghosh AK, Vaughan DE. PAI-1 in tissue fibrosis. J Cell Physiol. (2012) 227:493-507. doi: 10.1002/jcp.22783

81. Liu J, Li Y, Liu L, Wang Z, Shi C, Cheng Z, et al. Double knockdown of PHD1 and Keap1 attenuated hypoxia-induced injuries in hepatocytes. Front Physiol. (2017) 8:291. doi: 10.3389/fphys.2017.00291

82. Iwaisako K, Brenner DA, Kisseleva T. What's new in liver fibrosis? The origin of myofibroblasts in liver fibrosis. J Gastroenterol Hepatol. (2012) 27(Suppl 2):65-8. doi: 10.1111/j.1440-1746.2011.07002.x

83. Copple BL, Bai S, Burgoon LD, Moon JO. Hypoxia-inducible factor1alpha regulates the expression of genes in hypoxic hepatic stellate cells important for collagen deposition and angiogenesis. Liver Int. (2011) 31:23044. doi: 10.1111/j.1478-3231.2010.02347.x

84. Copple BL, Bai S, Moon JO. Hypoxia-inducible factor-dependent production of profibrotic mediators by hypoxic Kupffer cells. Hepatol Res. (2010) 40:530-9. doi: 10.1111/j.1872-034X.2010.00635.x

85. Copple BL, Kaska S, Wentling C. Hypoxia-inducible factor activation in myeloid cells contributes to the development of liver fibrosis in cholestatic mice. J Pharmacol Exp Ther. (2012) 341:307-16. doi: 10.1124/jpet.111.189340

86. Schadde E, Tsatsaris C, Swiderska-Syn M, Breitenstein S, Urner M, Schimmer $\mathrm{R}$, et al. Hypoxia of the growing liver accelerates regeneration. Surgery. (2017) 161:666-79. doi: 10.1016/j.surg.2016.05.018

87. Mejias M, Garcia-Pras E, Tiani C, Miquel R, Bosch J, Fernandez M. Beneficial effects of sorafenib on splanchnic, intrahepatic, and portocollateral circulations in portal hypertensive and cirrhotic rats. Hepatology. (2009) 49:1245-56. doi: 10.1002/hep.22758

88. Yang L, Kwon J, Popov Y, Gajdos GB, Ordog T, Brekken RA, et al. Vascular endothelial growth factor promotes fibrosis resolution and repair in mice. Gastroenterology. (2014) 146:1339-50 e1. doi: 10.1053/j.gastro.2014.01.061

89. Novo E, Cannito S, Zamara E, Valfre di Bonzo L, Caligiuri A, Cravanzola $\mathrm{C}$, et al. Proangiogenic cytokines as hypoxia-dependent factors stimulating migration of human hepatic stellate cells. Am J Pathol. (2007) 170:194253. doi: 10.2353 /ajpath.2007.060887

90. Wang YQ, Luk JM, Ikeda K, Man K, Chu AC, Kaneda K, et al. Regulatory role of vHL/HIF-1alpha in hypoxia-induced VEGF production in hepatic stellate cells. Biochem Biophys Res Commun. (2004) 317:35862. doi: 10.1016/j.bbrc.2004.03.050

91. Luedde T, Schwabe RF. NF-kappaB in the liver-linking injury, fibrosis and hepatocellular carcinoma. Nat Rev Gastroenterol Hepatol. (2011) 8:10818. doi: 10.1038/nrgastro.2010.213

92. Oakley F, Teoh V, Ching ASG, Bataller R, Colmenero J, Jonsson JR, et al. Angiotensin II activates I kappaB kinase phosphorylation of RelA at Ser 536 to promote myofibroblast survival and liver fibrosis. Gastroenterology. (2009) 136:2334-44 e1. doi: 10.1053/j.gastro.2009.02.081

93. Bracken CP, Whitelaw ML, Peet DJ. Activity of hypoxia-inducible factor 2alpha is regulated by association with the NF-kappaB essential modulator. $J$ Biol Chem. (2005) 280:14240-51. doi: 10.1074/jbc.M409987200

94. Rius J, Guma M, Schachtrup C, Akassoglou K, Zinkernagel AS, Nizet $\mathrm{V}$, et al. NF-kappaB links innate immunity to the hypoxic response through transcriptional regulation of HIF-1alpha. Nature. (2008) 453:80711. doi: $10.1038 /$ nature06905

95. D'Ignazio L, Bandarra D, Rocha S. NF-kappaB and HIF crosstalk in immune responses. FEBS J. (2016) 283:413-24. doi: 10.1111/febs. 13578

96. Cai H, Bai Z, Ge RL. Hypoxia-inducible factor-2 promotes liver fibrosis in non-alcoholic steatohepatitis liver disease via the NF-kappaB signalling pathway. Biochem Biophys Res Commun. (2021) 540:6774. doi: 10.1016/j.bbrc.2021.01.002

97. Mesarwi OA, Moya EA, Zhen X, Gautane M, Zhao H, Wegbrans Giro P, et al. Hepatocyte HIF-1 and intermittent hypoxia independently impact liver fibrosis in murine NAFLD. Am J Respir Cell Mol Biol. (2021). doi: 10.1165/rcmb.2020-0492OC

98. Yoshiji H, Kuriyama S, Yoshii J, Ikenaka Y, Noguchi R, Hicklin DJ, et al. Vascular endothelial growth factor and receptor interaction is a prerequisite for murine hepatic fibrogenesis. Gut. (2003) 52:134754. doi: 10.1136/gut.52.9.1347

99. Palazon A, Goldrath AW, Nizet V, Johnson RS. HIF transcription factors, inflammation, and immunity. Immunity. (2014) 41:51828. doi: 10.1016/j.immuni.2014.09.008

100. Cummins EP, Keogh CE, Crean D, Taylor CT. The role of HIF in immunity and inflammation. Mol Aspects Med. (2016) 47-48:2434. doi: 10.1016/j.mam.2015.12.004

101. Sadiku P, Walmsley SR. Hypoxia and the regulation of myeloid cell metabolic imprinting: consequences for the inflammatory response. EMBO Rep. (2019) 20. doi: 10.15252/embr.201847388

102. Watts ER, Walmsley SR. Inflammation and hypoxia: HIF and PHD isoform selectivity. Trends Mol Med. (2019) 25:3346. doi: 10.1016/j.molmed.2018.10.006

103. Taylor CT, Cummins EP. The role of NF-kappaB in hypoxiainduced gene expression. Ann N Y Acad Sci. (2009) 1177:17884. doi: 10.1111/j.1749-6632.2009.05024.x

104. Caligiuri A, Gentilini A, Marra F. Molecular pathogenesis of NASH. Int J Mol Sci. (2016) 17:1575. doi: 10.3390/ijms17091575

105. Ouyang X, Han SN, Zhang JY, Dioletis E, Nemeth BT, Pacher P, et al. Digoxin suppresses pyruvate kinase M2-promoted HIF-1alpha transactivation in steatohepatitis. Cell Metab. (2018) 27:1156. doi: 10.1016/j.cmet.2018.04.007

106. Wang $X$, de Carvalho Ribeiro $M$, Iracheta-Vellve A, Lowe P, Ambade A, Satishchandran A, et al. Macrophage-specific hypoxia-inducible factor-1alpha contributes to impaired autophagic flux in nonalcoholic steatohepatitis. Hepatology. (2019) 69:545-63. doi: 10.1002/hep.30215

107. Bartneck M, Fech V, Ehling J, Govaere O, Warzecha KT, Hittatiya $\mathrm{K}$, et al. Histidine-rich glycoprotein promotes macrophage activation and inflammation in chronic liver disease. Hepatology. (2016) 63:131024. doi: 10.1002/hep. 28418

108. da Rosa DP, Forgiarini LF, Baronio D, Feijo CA, Martinez D, Marroni NP. Simulating sleep apnea by exposure to intermittent hypoxia induces inflammation in the lung and liver. Mediators Inflamm. (2012) 2012:879419. doi: 10.1155/2012/879419

109. Liu J, Li W, Zhu W, He W, Zhao H, Xiang Y, et al. Chronic intermittent hypoxia promotes the development of experimental nonalcoholic steatohepatitis by modulating Treg/Th17 differentiation. Acta Biochim Biophys Sin. (2018) 50:1200-10. doi: 10.1093/abbs/gmy131

110. Ost M, Doerrier C, Gama-Perez P, Moreno-Gomez S. Analysis of mitochondrial respiratory function in tissue biopsies and blood cells. Curr Opin Clin Nutr Metab Care. (2018) 21:33642. doi: 10.1097/MCO.0000000000000486

111. Perakakis N, Stefanakis K, Mantzoros CS. The role of omics in the pathophysiology, diagnosis and treatment of non-alcoholic fatty liver disease. Metabolism. (2020) 111S:154320. doi: 10.1016/j.metabol.2020.154320

112. Puchalska P, Crawford PA. Application of stable isotope labels for metabolomics in studies in fatty liver disease. Methods Mol Biol. (2019) 1996:259-72. doi: 10.1007/978-1-4939-9488-5_20

113. Sutton TR, Minnion M, Barbarino F, Koster G, Fernandez BO, Cumpstey AF, et al. A robust and versatile mass spectrometry platform for comprehensive assessment of the thiol redox metabolome. Redox Biol. (2018) 16:35980. doi: 10.1016/j.redox.2018.02.012

114. Aguilar Diaz De Leon J, Borges CR. Evaluation of oxidative stress in biological samples using the thiobarbituric acid reactive substances assay. $J$ Vis Exp. (2020) 159:e61122. doi: 10.3791/61122

115. Lee YS, Kim JW, Osborne O, Oh DY, Sasik R, Schenk S, et al. Increased adipocyte $\mathrm{O}_{2}$ consumption triggers HIF-1alpha, causing inflammation and insulin resistance in obesity. Cell. (2014) 157:1339-52. doi: 10.1016/j.cell.2014.05.012 
116. Choe SS, Shin KC, Ka S, Lee YK, Chun JS, Kim JB. Macrophage HIF-2alpha ameliorates adipose tissue inflammation and insulin resistance in obesity. Diabetes. (2014) 63:3359-71. doi: 10.2337/db13-1965

117. Magri S, Paduano D, Chicco F, Cingolani A, Farris C, Delogu G, et al. Nonalcoholic fatty liver disease in patients with inflammatory bowel disease: beyond the natural history. World J Gastroenterol. (2019) 25:567686. doi: 10.3748 /wjg.v25.i37.5676

118. Shah YM. The role of hypoxia in intestinal inflammation. Mol Cell Pediatr. (2016) 3:1. doi: 10.1186/s40348-016-0030-1

119. Xie C, Yagai T, Luo Y, Liang X, Chen T, Wang Q, et al. Activation of intestinal hypoxia-inducible factor 2alpha during obesity contributes to hepatic steatosis. Nat Med. (2017) 23:1298-308. doi: 10.1038/ nm.4412

120. Gonzalez FJ, Xie C, Jiang C. The role of hypoxia-inducible factors in metabolic diseases. Nat Rev Endocrinol. (2018) 15:21-32. doi: 10.1038/s41574-018-0096-Z
Conflict of Interest: The authors declare that the research was conducted in the absence of any commercial or financial relationships that could be construed as a potential conflict of interest.

Publisher's Note: All claims expressed in this article are solely those of the authors and do not necessarily represent those of their affiliated organizations, or those of the publisher, the editors and the reviewers. Any product that may be evaluated in this article, or claim that may be made by its manufacturer, is not guaranteed or endorsed by the publisher.

Copyright (C) 2021 Holzner and Murray. This is an open-access article distributed under the terms of the Creative Commons Attribution License (CC BY). The use, distribution or reproduction in other forums is permitted, provided the original author(s) and the copyright owner(s) are credited and that the original publication in this journal is cited, in accordance with accepted academic practice. No use, distribution or reproduction is permitted which does not comply with these terms. 